\title{
Early feeding and risk of Juvenile idiopathic arthritis: a case control study in a prospective birth cohort
}

\author{
Erik Kindgren ${ }^{1,2^{*}}$ (D), Mats Fredrikson ${ }^{3,4}$ and Johnny Ludvigsson ${ }^{2}$
}

\begin{abstract}
Background: Juvenile idiopathic arthritis (JIA) is considered to be an autoimmune disease, but the etiology is unknown. We decided to study the influence of early nutrition on later development of JIA.

Methods: All parents with children born between October 1, 1997 and October 1, 1999 in Southeast Sweden were asked to participate in the ABIS prospective cohort study (All Babies in Southeast Sweden), At 1 year, questionnaires with information on breastfeeding and introduction of foods were completed by 10,565 families. We identified 32 children with JIA and 111 children with non-chronic arthritis with completed questionnaires after delivery and after 1 year. A multivariable logistic regression model, adjusted for relevant factors, was performed to calculate the association between JIA and feeding during the first year of life.

Results: An increased risk for JIA was found in children who had breast fed for less than 4 months, as opposed to those who were continued on breast milk beyond 4 months of age (aOR $3.5,95 \% \mathrm{Cl} 1.4-8,5 ; p=0.006$ ). A short duration of exclusive as well as total breastfeeding was associated with an increased risk of JIA (aOR 1.3, 95\% Cl 1.11.6; $p=0.008$ and aOR 1.2, 95\% Cl 1.1-1.3; $p<0.001$ ). All associations between breastfeeding and JIA persisted after adjustment. There was no relationship between early nutrition and non-chronic arthritis.

Conclusions: Our results indicate that there are different disease mechanisms for different types of arthritis in childhood. Longer duration of breastfeeding (both total and exclusive) may protect against development of JIA. Mothers should be encouraged to breast-feed their babies exclusively, if at all possible, for 4 months and continue partial breastfeeding for an extended time when foreign proteins are introduced.
\end{abstract}

Keywords: Juvenile idiopathic arthritis (JIA), Arthritis, Epidemiology, Autoimmunity, Nutrition, Reactive arthritis, Breastfeeding, Rheumatic disease

\section{Background}

Juvenile idiopathic arthritis (JIA), the most common chronic rheumatic disease of childhood, is a collection of chronic pediatric arthritis characterized by onset before 16 years of age and the presence of arthritis (inflammation of the synovium with thickening of the synovial lining and accumulation of synovial fluid) for at least 6 weeks [1].

JIA is considered to be an autoimmune disease, which is a result of an immune reaction caused or triggered by

\footnotetext{
* Correspondence: erik@kindgren.org

${ }^{1}$ Department of Pediatrics, Västervik Hospital, Västervik, Sweden

2Division of Pediatrics, Department of Clinical and Experimental Medicine,

Linköping University, Linköping, Sweden

Full list of author information is available at the end of the article
}

environmental factors in a genetically susceptible individual. The starting point of autoimmunity leading to this disease is still unknown.

The mother's immunological memory is transferred to her infant via breast milk, and breast milk contains a variety of immune-modulating compounds, both immune cells and their products such as cytokines. Breastfeeding leads to immunological imprinting and programming of the infant [2], and thereby contributes to the maturity of the infant's immune system [3-5]. It has been proposed that breastfeeding might protect against the development of JIA [6]. Another study noted a tendency of shorter breastfeeding among children who later developed oligoarticular JIA [7]. However, breastfeeding did not show 
any protective effect against JIA in subsequent studies [8-10]. A cohort study from UK recently showed that breastfeeding is associated with milder onset of JIA [11]. Previous studies have been retrospective case-control studies. To get more reliable unbiased results, we have analyzed data on early feeding of children in a prospective cohort study of the general population, the ABIS study (All Babies in Southeast Sweden). The primary aim of this study was to explore feeding factors, such as breastfeeding, in relation to risk of later development of JIA. Increased knowledge of the role of early nutrition of the child and its association with autoimmunity is of great importance for public health, as dietary recommendations may help to prevent these chronic diseases.

\section{Methods}

In Sweden, all children aged 0-18 years with diagnosed JIA or Rheumatoid Arthritis (RA) are treated at pediatric clinics in hospitals or pediatric rheumatology clinics. The Swedish National Patient Register is maintained by the Swedish National Board of Health and Welfare (http:// www.socialstyrelsen.se/english). This population-based register, was launched in 1964, but complete coverage of all in-patient care in Sweden did not begin until 1987 [12]. Currently, more than $99 \%$ of all somatic and psychiatric hospital discharges are registered. Since 2001 the register also covers outpatient visits from both private and public caregivers. Diseases are coded using International Classification of Diseases (ICD) codes and for each healthcare contact several items are recorded, including personal identity number (PIN - a unique 10-digit number assigned to all Swedish residents) [13], date of admission and discharge, hospital and primary and secondary diagnoses.

The Swedish JIA-registry started in 2009 with the primary goal to follow all children on cytokine modulators, but later expanded to all children with JIA. In 2014 there were 1700 patients included and coverage was almost complete. Through the unique PIN, information on each individual patient can be linked to other registries.

\section{Participants and design}

All parents with children born between October 1,1997 and October 1,1999 in Southeast Sweden $(n=21,700)$ were asked to participate in the ABIS study, a prospective cohort study. 17,055 (78.6\%) out of the 21,700 families who were asked gave their informed consent to participate. Questionnaires were completed at birth and then at the ages 1, 2.5, 5, 8 and 11-13. Different biological samples were collected. A diary was used for daily registration of certain facts related to nutrition, infections etc. during the first year of life. In the questionnaires, parents were asked for the duration of breastfeeding. Exclusive breastfeeding is defined as the infant receiving only breast-milk. Partial breastfeeding is defined as breastfeeding in addition to formula or other food (corresponding to WHO's definition of complementary feeding) [14]. Total duration of breastfeeding is defined as the length of any kind of breastfeeding.

We also have considered a possible influence by the introduction of infant formula or gruel, cow's milk and gluten, heredity, mode of delivery, and various socioeconomic variables such as civil status, parental age, education, smoking habits, and whether or not the parents were born outside Sweden. Questions pertaining to the duration of exclusive breastfeeding and total duration of breastfeeding, as well as the time for introduction of formulas and other semi-solid (infant formula, follow-on formula) and solid foods (porridge, first solid food) had response alternatives of months (after birth), usually from 1 to $\geq 9$. The 1 year questionnaires were completed by 10,883 families, and in addition a detailed diary during the first year of life, including the exact time (date) of weaning and introduction of different food items, was collected for 9849 children. All subjects with missing values were excluded from the statistical model.

Using the Swedish personal identification number [13], we linked data between the ABIS-cohort and The Swedish National Patient Register [12]. Diagnoses are classified according to the ICD, versions 8 to 10 . We identified 59 children, born between October 1, 1997 and October 1, 1999 in the ABIS region, with inpatient hospital discharges or outpatient visits who had a diagnostic code of JIA (M08-09 on ICD 8-10) and had accepted to participate in ABIS. After communication with all pediatric rheumatologists at local hospitals who reviewed the medical records of all 59 patients, 17 patients were excluded due to misdiagnosis (mostly arthritis that later proved to be reactive arthritis). Three of the 59 children had moved out of the ABIS region, but could be found with the PIN. Of the remaining 42 children, 41 guardians had completed the screening questionnaire after delivery, and 32 of them had completed both the screening questionnaire after delivery and the 1 year follow up questionnaire. 29 of 32 had also completed the diary during the first year. All cases of JIA were controlled via The Swedish pediatric JIA-registry.

We identified 111 patients in the same cohort with an episode of a transient non-chronic arthritis, with only one joint involved with a maximum duration of 6 weeks. $12 \%(13 / 111)$ of them were diagnosed with reactive arthritis and 88\% (95/111) with unspecified arthritis (M02 respective M13 on ICD 8-10). The risk of rheumatic disease is considered to be minimal in this group, with only one period of monoarthritis with a short duration throughout the 17-19 year-long follow up period.

Data were analyzed as a case-control study with two groups of cases (JIA and non-chronic arthritis) and remaining children as controls. 


\section{Statistics}

The normality for independent variables was revised both graphically and by the Shapiro-Wilk test and, subsequently, homogeneity of variance was tested using Levene's test.

Univariate logistic regression was used to calculate odds ratio (OR) and $95 \%$ confidence intervals (95\% CIs). We used JIA as the dependent variable. Duration of breastfeeding (continuous as months from the 1-year questionnaire and as days from the diary), age of introduction of food (continuous as months) and possible confounding factors (listed below) associated with incidence of JIA were analyzed. In the second statistical model we used the same covariates but changed the dependent variable to non-chronic arthritis. Duration of breastfeeding was also dichotomized to shorter or longer than 4 and 6 months respectively, according to the recommendation to introduce solid food during 4 to 6 months. Adjusted odds ratio (aOR) was calculated in the final multivariable logistic regression model. Variables with $p<0.1$ in the univariate analyses were included in the adjusted model as possible confounding factors associated breastfeeding. Attributable risk percent was calculated using the formula two in Rockhill et al. [15].

All $P$-values are two-tailed. A $P$-value below 0.05 and a 95\% CI not overlapping the null value 1.00 for the OR were regarded as statistically significant.

Possible confounding factors were: heredity for rheumatism (JIA or RA in first- and second-degree relatives), parity, mode of delivery, preterm birth, introduction of formula,

parent-reported infections during child's first year of life (cold, fever, throat infection/tonsillitis, influenza, otitis media, pneumonia, measles, rubella, mumps, pertussis, varicella, urinary tract infection, gastroenteritis and other infection), mother's civil status, parental age, education, smoking habits, and whether or not the parents were born outside Sweden.

Statistics were calculated using the Statistical Package for Social Science (SPSS 20.0 software; SPSS Inc., Chicago, IL, USA).

\section{Results}

\section{Cases}

32 cases of JIA with complete questionnaires after delivery and at the 1 year follow up were identified. The most common JIA category was oligoarticular disease (Table 1). The unclassified based on the ILAR-criteria [1], either not fulfill criteria for any category or they meet categorization for 2 subtypes. Family history of RA/JIA in first-degree family member was present in only one patient in both the JIA-group (3\%) and the group with non-chronic arthritis (1\%) compared with 130 controls
(1\%) (Table 1). A family history of RA/JIA in a seconddegree family member was more common; three patients in the JIA-group (9\%), 16 in the group with nonchronic arthritis (14\%), and 940 of the controls (9\%).

\section{Exclusive breastfeeding}

One-year post-birth questionnaire data from the whole ABIS cohort 1 year after birth showed that the mean duration of exclusive breastfeeding was four and a half months, the same for boys and girls. The corresponding mean in the JIA-group was three and a half months. At the age of 3 months $78.4 \%$ of the unaffected children were exclusively breastfed compared to $61.3 \%$ in the affected (JIA) group (Fig. 1). A short duration of exclusive breastfeeding was significantly associated with an increased risk of JIA in logistic regression with continuous variables, both by months (from the one-year post-birth questionnaire) and by days (from the diary).

Dichotomized, exclusive breastfeeding less than 4 months, had highest statistical significance, associated with increased risk of developing JIA (aOR 2.50, 95\% CI 1.20-5.56, $p=0.029$ ), and attributable risk percent at $60.02 \%$. Stratified data for end of breastfeeding are given in Table 2.

All associations between exclusive breastfeeding and JIA remained statistically significant when factors such as parental smoking, parents' education, parental country of birth, parental age, heredity for rheumatism, preterm birth and introduction of formula and infections during the first year of life were included in the analysis (aOR 1.30, 95\% CI 1.07-1.57; $p=0.008$ ).

The group with non-chronic arthritis had the same mean (4.55 months) as the general population and there was no significant association between exclusive breastfeeding and non-chronic arthritis.

\section{Risk factors associated with short-term exclusive breastfeeding}

The main logistic regression showed that short-term exclusive breastfeeding was positively associated with older maternal age (aOR 1.42, 95\% CI 1.25-1.42), paternal age (over 37 years) (aOR 0.74; 95\% CI 0.55-0.99; $p=0.045$ ), maternal BMI $>30 \quad$ (aOR 1.07; 95\% CI 1.05-1.09; $p<0.001$ ) and with maternal smoking (aOR 1.43; 95\% CI $1.05-1.95 ; p=0.023)$. Short-term exclusive breastfeeding was more often reported by single parents $(\mathrm{aOR}$ 2.10; 95\% CI 1.43-3.09; $p<0.001$ ).

Short-term exclusive breastfeeding was less common if one of the parents had a university degree (Mother: aOR 0.74; 95\% CI 0.61-0.90; $p=0.003$, Father: aOR 0.73; 95\% CI $0.58-0.92 ; p=0.008)$.

\section{Total duration of breastfeeding}

The mean duration of total breastfeeding was 1.5 months less in the affected children than the unaffected children 
Table 1 Risk of JIA and non-chronic arthritis according to early feeding and family history. P-values from logistic regression. Classification according to ILAR criteria. The number ( $\mathrm{n}$ ) and proportion (\%) of patients in each category

\begin{tabular}{|c|c|c|c|c|c|c|c|c|c|}
\hline & \multirow{3}{*}{$\begin{array}{l}\text { Controls } \\
(n=10,883)\end{array}$} & \multirow{2}{*}{\multicolumn{3}{|c|}{$\begin{array}{l}\text { Non-chronic arthritis } \\
\begin{array}{l}\text { Univariate analysis }{ }^{\mathrm{a}} \text { vs } \\
\text { controls }\end{array}\end{array}$}} & \multicolumn{5}{|l|}{$J \mathrm{~A}$} \\
\hline & & & & & \multicolumn{3}{|c|}{ Univariate analysis vs controls } & \multicolumn{2}{|c|}{$\begin{array}{l}\text { Adjusted for potential } \\
\text { confounding factors }^{b}\end{array}$} \\
\hline & & $(n=111)$ & OR $(95 \% \mathrm{Cl})$ & $\mathrm{p}$ & $(n=32)$ & OR $(95 \% \mathrm{Cl})$ & $\mathrm{p}$ & $\mathrm{aOR}(95 \% \mathrm{Cl})$ & $\mathrm{p}$ \\
\hline \multicolumn{10}{|l|}{ Duration of exclusive breastfeeding } \\
\hline Mean (SD) months & $4.5(1.9)$ & $4.6(1.9)$ & & & $3.6(1,6)$ & & & & \\
\hline Median (Range) months & $4(1-9)$ & $4(1-9)$ & $1.0(0.9-1.1)$ & 0.879 & $4(1-7)$ & $1.3(1.1-1.6)$ & 0.004 & $1.3(1.1-1.6)$ & 0.008 \\
\hline Mean (SD) days ${ }^{c}$ & $126(60)$ & $135(61)$ & & & $109(55)$ & $1.0(1.0-1.0)$ & 0.005 & $1.0(1.0-1.0)$ & 0.009 \\
\hline Exclusive breastfeeding <4 months ( $\mathrm{n}$ ) & $5351(52.3 \%)$ & $61(51 \%)$ & $1.3(0.9-2.1)$ & 0.220 & $22(73 \%)$ & $2.5(1.2-5.6)$ & 0.026 & $2.5(1.2-5.6)$ & 0.029 \\
\hline \multicolumn{10}{|l|}{ Duration of total breastfeeding } \\
\hline Mean (SD) months & $7.1(2.4)$ & $7.2(2.4)$ & & & $5.7(2.8)$ & & & & \\
\hline Median (Range) months & $8(1-9)$ & $8(1-9)$ & $0.99(0.9-1.1)$ & 0.940 & $6(1-9)$ & $1.2(1.1-1.4)$ & $<0.001$ & $1.2(1.1-1.3)$ & $<0.001$ \\
\hline Mean (SD) days ${ }^{d}$ & $219(82)$ & $225(90)$ & $0.97(0.9-1.1)$ & 0.982 & $166(100)$ & $1.0(1.0-1.0)$ & $<0.001$ & $1.0(1.0-1.0)$ & $<0.001$ \\
\hline Total breastfeeding $<4$ months ( $n$ ) & 1694(16\%) & 19 (18\%) & $1.1(0.7-1.8)$ & 0.715 & $11(36 \%)$ & $2.8(1.3-5.8)$ & 0.006 & $2.8(1.3-5.7)$ & 0.009 \\
\hline Total breastfeeding <6 months ( $n$ ) & $3166(31 \%)$ & $33(31 \%)$ & $1.0(0.7-1.5)$ & 0.981 & $19(61 \%)$ & $3.6(1.7-7.4)$ & $<0.001$ & $3.5(1.6-6.2)$ & $<0.001$ \\
\hline \multicolumn{10}{|l|}{ Introduction of cow's milk formula } \\
\hline Mean (SD) months & $4.8(2.5)$ & $4.9(2.7)$ & $1.0(0.9-1.1)$ & 0.770 & $3.9(2.2)$ & $1.2(1.0-1.3)$ & 0.052 & $1.0(1.0-1.3)$ & 0.055 \\
\hline Median (Range) months & $5(1-9)$ & $6(1-9)$ & & & $4(1-9)$ & & & & \\
\hline \multicolumn{10}{|l|}{ Introduction of gluten } \\
\hline Mean (SD) months & $6.0(1.39)$ & $5.9(1.4)$ & $1.0(0.9-1.2)$ & 0.563 & $5.8(1.27)$ & $1.1(0.9-1.4)$ & 0.483 & No analysis per & formed \\
\hline Median (Range) months & $6(1-9)$ & $6(3-9)$ & & & $6(4-8)$ & & & & \\
\hline \multicolumn{10}{|l|}{ Family history / Heredity for JIA/RA } \\
\hline Mother with RA (n) & $100(1 \%)$ & $1(1 \%)$ & $0.9(0.3-6.7)$ & 0.941 & $1(3 \%)$ & $3.5(0.5-2.6)$ & 0.223 & No analysis per & formed \\
\hline Father with RA (n) & $31(0 \%)$ & $0(0 \%)$ & 0 & 1.000 & $0(0 \%)$ & 0 & 1.000 & No analysis per & formed \\
\hline Siblings with JIA/RA (n) & $0(0 \%)$ & $0(0 \%)$ & 0 & 1.000 & $0(0 \%)$ & 0 & 1.000 & No analysis per & formed \\
\hline 2nd degree family member with RA ( $n$ ) & $940(9 \%)$ & $16(14 \%)$ & $1.7(0.98-2.8)$ & 0.06 & $3(9 \%)$ & $1.7(0.98-2.8)$ & 0.910 & No analysis per & formed \\
\hline \multicolumn{10}{|l|}{ Category at Onset (ILAR) (n) } \\
\hline Oligoarticular $^{a}$ & & & & & $14(44 \%)$ & & & & \\
\hline Polyarticular ${ }^{\mathrm{e}}$ & & & & & $4(13 \%)$ & & & & \\
\hline Enthesitis-related arthritis & & & & & $2(6 \%)$ & & & & \\
\hline Psoriatic arthritis & & & & & $3(9 \%)$ & & & & \\
\hline Systemic & & & & & $4(13 \%)$ & & & & \\
\hline Unclassifiable & & & & & 5 (16\%) & & & & \\
\hline
\end{tabular}

a Patients with oligoarticular disease, not possible to classify as extended or persistent because of missing data

${ }^{b}$ Potential confounding factors were heredity for rheumatism (JIA or RA in first- and second-degree relatives), parity, mode of delivery, preterm birth, infections

during the first year of life, introduction of formula, the parents' level of education, smoking and age as well as country of birth

'Data from diary: Control $(n=8913)$; Non-chronic arthritis $(n=79)$; JIA $(n=29)$

${ }^{\mathrm{d}}$ Data from diary: Control $(n=9732)$; Non-chronic arthritis $(n=105)$; JIA $(n=31)$

e Patients with polyarticular disease, not possible to classify as RF positive or negative because of missing data

(5.65 v. 7.09 months). The percentages of control infants who were breastfed at 3,6 and $\geq 9$ months of age were 87.9, 69.1 and 43.6, respectively. The corresponding percentages for any breastfeeding in the JIA-affected group were 73.3, 40.0 and 26.7 (Fig. 1). A short duration of total breastfeeding was associated with an increased risk of JIA in logistic regression with continuous variables.
Total duration of breastfeeding less than 4 months was associated with increased risk of developing JIA (aOR 2.75, 95\% CI 1.33-5.71, $p=0.009$ ), with a attributable risk percent at $64,17 \%$.

The adjusted odds ratio for increased risk of JIA was 3.5 (95\% CI 1.6-6,2; $p=0.001$ ) if the total duration of breastfeeding stopped at or before 6 months of age, with a attributable risk percent at $71.97 \%$. 

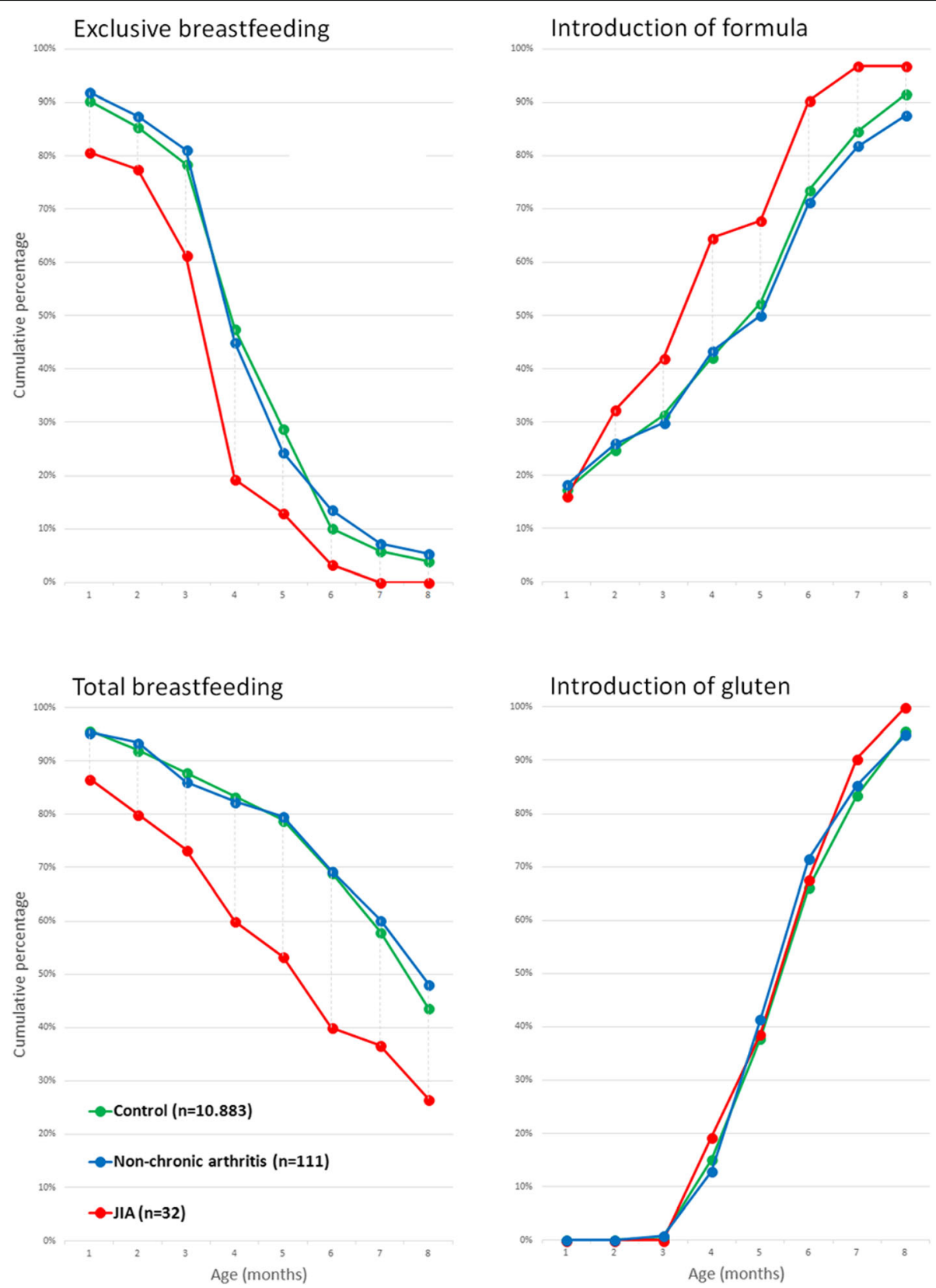

Fig. 1 Cumulative percentages for duration of exclusive and total breastfeeding, as well as cumulative percentages for time of introduction of formula and gluten

Estimates between total duration of breastfeeding and JIA remained significant after adjusting for potential confounders including parental smoking, education, parental country of birth, parental age, heredity, preterm birth, introduction of formula, and infections during the first year of life (aOR 1.20, 95\% CI 1.07$1.34 p<0.001)$.

Non-chronic arthritis had the same mean duration (7.15 months) as the general population and there were no significant associations.
Risk factors associated with total duration of breastfeeding

Both maternal $(P<0.001)$ and paternal age $(P<0.001)$ were positively associated with the total duration of breastfeeding. Short-term exclusive breastfeeding was more often reported by younger mothers.

\section{Introduction of cow's milk formula}

According to the questionnaire at 1 year, the mean age of introduction of formulas containing cow's milk was 1 
Table 2 End of breastfeeding comparison between JIA and Non-chronic arthritis vs. Controls. OR and P-values from logistic regression

\begin{tabular}{|c|c|c|c|c|c|c|c|}
\hline & \multirow{2}{*}{$\begin{array}{l}\text { Controls } \\
(n=10,189)\end{array}$} & \multicolumn{3}{|c|}{ Non-chronic arthritis } & \multicolumn{3}{|l|}{$J \mathrm{~A}$} \\
\hline & & $(n=105)$ & OR $(95 \% \mathrm{Cl})$ & $p$ & $(n=29)$ & OR $(95 \% \mathrm{Cl})$ & $p$ \\
\hline \multicolumn{8}{|l|}{ End of exclusive breastfeeding } \\
\hline Months 1-4 (0-120 days) & $3261(37 \%)$ & $27(34 \%)$ & 1 (ref) & 0.700 & $16(57 \%)$ & 1 (ref) & 0.023 \\
\hline Months 5-8 (121-240 days) & $5374(60 \%)$ & $48(61 \%)$ & $0.9(0.6-1.3)$ & 0.458 & $12(43 \%)$ & $0.3(0.1-0.7)$ & 0.006 \\
\hline Months 9-12 (241-365 days) & $269(3 \%)$ & $4(5 \%)$ & $1.1(0.5-2.8)$ & 0.800 & $0(0 \%)$ & 0 & 0.994 \\
\hline \multicolumn{8}{|l|}{ End of total breastfeeding } \\
\hline Months 1-4 (0-120 days) & $1579(15 \%)$ & $20(19 \%)$ & 1 (ref) & 0.558 & $11(38 \%)$ & 1 (ref) & 0.003 \\
\hline Months 5-8 (121-240 days) & $3569(35 \%)$ & $34(32 \%)$ & $0.8(0.4-1.3)$ & 0.315 & $11(38 \%)$ & $0.4(0.2-1.0)$ & 0.056 \\
\hline Months 9-12 (241-365 days) & $5041(50 \%)$ & $51(49 \%)$ & $0.8(0.5-1.3)$ & 0.397 & $7(24 \%)$ & $0.2(0.1-0.5)$ & 0.001 \\
\hline
\end{tabular}

month less in the JIA affected group than the unaffected (3.94 v. 4.82 months) (Fig. 1). In logistic regression analysis, early introduction of cow's milk formula (before 4 months of age) was associated with an increased risk of developing JIA (OR 2.49, 95\% CI 1.19-5.21; $p=0.015$ ). There was only a tendency of association between introduction of cow's milk and JIA (aOR 0.87, 95\% CI 0.997$1.32 ; p=0.055)$ in logistic regression with continuous variables.

Non-chronic arthritis had the same mean (4.92 months) as the general population and there were no significant associations.

The age at introduction of formulas containing cow's milk correlated negatively with both duration of exclusive breastfeeding $(\mathrm{r} 0.6, p<0.001)$ and total duration of breastfeeding (r 0.575, $p<0.001)$.

\section{Introduction of gluten}

We did not observe any significant association between age at introduction of gluten and risk of JIA or nonchronic arthritis (Fig. 1).

\section{Discussion}

In the present study, we found that a short total duration of breastfeeding as well as a short duration of exclusive breastfeeding was associated with an increased risk of JIA. An early introduction of formula $(<4$ months of age) was associated with an increased risk of JIA. All associations remained statistically significant when potential confounders were included in the model.

Children with non-chronic arthritis had the same pattern of breastfeeding and introduction of formula as the general population. This suggests different disease mechanisms for different types of arthritis in children. Breastfeeding appears to be involved in the origin of autoimmunity causing Juvenile idiopathic arthritis.

\section{Breastfeeding data}

The average breastfeeding duration in our study was similar to that among infants in Norway [16], Iceland [17] and Denmark [18], showing a relatively high prevalence of breastfeeding in Scandinavia compared with other parts of the Western world [19-21].

The data on total duration of breastfeeding is in good agreement with data from Official Statistics of Sweden [22] for the same area during the study period 1997-1999. Data is also consistent with the breastfeeding prevalence in the entire country during the years 1997-1999 (The National Board of Health and Welfare, 2001, . This indicates that the frequency of breastfeeding in ABIS infants during 1997-1999 was in line with current national recommendations, i.e. almost $85 \%$ of infants were breastfed until 4 months of age and more than $90 \%$ were introduced to solid food during the recommended 4 to 6 months.

\section{Study strengths and limitations}

Earlier studies on the association between breastfeeding and JIA/JCA are all retrospective, and the results may be compromised by recall bias. Mason et al. [6] showed that children with Juvenile Rheumatoid Arthritis were less likely, then their matched controls, to have been breastfed. This could not be confirmed in subsequent studies [8-10]. However, these reports have mainly excluded children with Enthesitis-related arthritis and Psoriatic arthritis. In a relatively large study, Hyrich et al. recently showed that breastfeeding is associated with milder onset of JIA [11]. This, in addition to our results, provides the most reliable evidence so far for an association between breastfeeding and JIA. Breastfeeding may be associated with lesser occurrence, milder or delayed onset of this autoimmune disease.

Our study has several notable strengths. First, our prospective study design avoids the potential recall and selection biases of retrospective, case-control studies which collect data on diet, nutrition, feeding practice and lifestyle after the diagnosis of JIA. Second, all cases of JIA collected through the unique 10-digit PIN with 
codes from the Swedish National Patient Register have been confirmed via The Swedish pediatric JIA-registry and the medical records, a significant advantage over studies that rely on self-report. Third, the availability of detailed information on parental smoking, socio economic factors, parental age and heredity, and other important early life factors allowed us to control for a number of potential confounding factors that may have influenced our observed associations. Finally, we have detailed information regarding other potential early life factors, including infectious diseases and early exposure to antibiotics, which may also influence risk of JIA.

Even though we find significant correlations one has to be cautious in the conclusions. A limitation of our study is the small patient sample, due to the nature of the study i.e. a birth cohort of a relative rare disease. There are large variations in the clinical severity of the disease between the JIA categories. Therefore, different categories of JIA should be studied as separate groups $[23,24]$. The patient sample in this study was too small to allow subgroup analysis.

Another weakness of the current study could be that the nutritional data was collected from the questionnaire at 1 year after birth, and there is a risk of recall bias [25]. However, this risk should not be overestimated as Launer et al. [26] have shown that mothers may well be aware of the breastfeeding duration of their latest child. When we compare breastfeeding data from the 1 year questionnaires and from the diary, the durations were comparable, indicating minimal risk of recall bias.

Although this is a cohort study we have chosen to analyze it with a case-control design since the exposure, duration of breastfeeding, is a continuous variable.

\section{Possible mechanisms underlying the protective effect of breastfeeding}

Socioeconomic status affects the duration of breastfeeding, as was shown in our study. However, the relationship between breastfeeding and JIA persisted after adjusting for socioeconomic differences.

In Sweden, most children receive cow's milk formula as their first source of foreign protein. The early introduction of cow's milk formula correlated significantly with both the duration of exclusive breastfeeding and the duration of total breastfeeding, which is a confounding factor in this kind of study [27]. However, the statistical analysis with logistic regression shows that exclusive duration of breastfeeding (OR 1.28) and adjusting for introduction of cow's milk formula (OR 1.32), indicating that breastfeeding has an independent protective effect against JIA.

Introduction of foreign proteins during breastfeeding favors the development of oral tolerance [28, 29]. Breast milk supports the development of tolerance [30-32]. Furthermore, breast milk is a source of other bioactive components such as hormones, immunoglobulins, enzymes and antiinflammatory agents, which probably stimulates the development of the immune system $[31,32]$.

Breastfeeding could be linked indirectly to JIA through the gut microbiota of the infant. Gut bacteria play a fundamental role in the human body by promoting intestinal homeostasis [33-36]. The dysbiosis of the gut microbiota has been associated to an increasing number of diseases, including autoimmune diseases such as diabetes and inflammatory bowel disease [35, 37, 38].

Breastfeeding has been reported to influence infant gut microbiota development [39-41]. Breast milk is recognized as one of the most important postpartum elements modulating metabolic and immunologic programming in the child [42]. Formula-fed infants have increased richness of species compared with breastfed infants [43]. However, a fully developed bacterial flora is established within the intestinal tract only with the start of solid food consumption. [44-47].

\section{Conclusions}

We cannot point to any specific mechanism effect, and we call for caution as the population-based finding is difficult to transfer to the individual situation. Still, the conclusion of our results is that a short duration of both total and exclusive breastfeeding seems to be associated with an increased risk of JIA in an unselected population of Swedish children. This indicates that breastfeeding might protect against development of JIA. Mothers should be encouraged to exclusively breastfeed their babies, if at all possible, for at least 4 months and continue partial breastfeeding during the time when foreign proteins are introduced via food.

\section{Abbrevations \\ ABIS: All Babies in Southeast Sweden; aOR: Adjusted odds ratio; $\mathrm{Cl}$ : Confidence Interval; ICD: International Classification of Diseases; ILAR: International League of Associations for Rheumatology; JCA: Juvenile Chronic Arthritis; JIA: Juvenile Idiopathic Arthritis; JRA: Juvenile Rheumatoid Arthritis; OR: Odds Ratio; PIN: Personal Identification Number; RA: Rheumatoid Arthritis; RR: Relative risk}

\section{Acknowledgement \\ We are very grateful to all children and families participating in the ABIS study, as well as to all staff members of the Child Health Service in the region where questionnaires were collected and biological samples taken. We thank the following colleagues for their participation: Ingela Danielsson (Linköping); Nils-Åke Nilsson (Motala); Per Lewander (Norrköping); Maria Ekelund and Sven Johansson (Jönköping); Johan Jonsson (Växjö); Sofia Hellerfelt (Karlskrona). We are also grateful to Lars Brudin for excellent help with statistics, and to Bo Magnusson and his colleagues at the Board of registry of the Swedish pediatric JIA-registry.}

\section{Availability of data and material}

All important data are within the text. The datasets generated and/or analyzed during the current study are not publicly available for privacy reasons, as well as ethical reasons, but are available from the ABIS Study group on reasonable request. 


\section{Funding}

This study was supported by The Research Unit of Kalmar County Council, Swedish Rheumatism Association and the Jerring Foundation. ABIS has been supported mainly by the Swedish Child Diabetes Foundation

(Barndiabetesfonden), the Juvenile Diabetes Research Foundation and the Medical Research Council of Southeast Sweden (FORSS). The funders had no role in study design, data collection and analysis, decision to publish, or preparation of the manuscript.

\section{Authors' contributions}

EK was responsible of the collection of JIA-patients, statistical analyses, figures, data interpretation and the writing of the manuscript. MF was responsible for critical review of the statistical analyses and review of the manuscript. JL, founder and project leader of the All Babies In Southeast Sweden study, had the primary responsibility for the study concept and design, collection of materials, and revision of the manuscript.

\section{Competing interests}

The authors declare that they have no competing interests.

\section{Consent for publication}

Not applicable.

\section{Ethics approval and consent to participate}

Parents or guardians gave their informed consent and the protocol of the ABIS study was approved by the Research Ethics Committees of the Faculty of Health Sciences, Linköping University, and the Medical Faculty, Lund University, Sweden 1997-02-19 Dnr 96,287.

\section{Author details}

${ }^{1}$ Department of Pediatrics, Västervik Hospital, Västervik, Sweden. ${ }^{2}$ Division of Pediatrics, Department of Clinical and Experimental Medicine, Linköping University, Linköping, Sweden. ${ }^{3}$ Division of Occupational and Environmental Medicine, Department of Clinical and Experimental Medicine, Linköping University, Linköping, Sweden. ${ }^{4}$ Forum Östergötland, Faculty of Medicine, Linköping University, Linköping, Sweden.

\section{Received: 4 April 2017 Accepted: 18 May 2017}

\section{Published online: 26 May 2017}

\section{References}

1. Petty RE, Southwood TR, Manners P, Baum J, Glass DN, Goldenberg J, et al. International league of associations for rheumatology classification of juvenile idiopathic arthritis: second revision, Edmonton, 2001. J Rheumatol. 2004;31(2):390-2.

2. Lemke $\mathrm{H}$, Lange $\mathrm{H}$. Is there a maternally induced immunological imprinting phase a la Konrad Lorenz? Scand J Immunol. 1999;50(4):348-54.

3. M'Rabet L, Vos AP, Boehm G, Garssen J. Breast-feeding and its role in early development of the immune system in infants: consequences for health later in life. J Nutr. 2008;138(9):1782S-90S.

4. Bjorksten B. Environmental influences on the development of the immune system: consequences for disease outcome. Nestle Nutr Workshop Ser Pediatr Program. 2008;61:243-54

5. Bjorksten B. Environment and infant immunity. Proc Nutr Soc. 1999;58(3):729-32.

6. Mason T, Rabinovich CE, Fredrickson DD, Amoroso K, Reed AM, Stein LD, et al. Breast feeding and the development of juvenile rheumatoid arthritis. J Rheumatol. 1995;22(6):1166-70.

7. Kasapcopur O, Tasdan Y, Apelyan M, Akkus S, Caliskan S, Sever L, et al. Does breast feeding prevent the development of juvenile rheumatoid arthritis? Rheumatol. 1998;25(11):2286-7.

8. Rosenberg AM. Evaluation of associations between breast feeding and subsequent development of juvenile rheumatoid arthritis. J Rheumatol. 1996;23(6):1080-2.

9. Ellis JA, Ponsonby AL, Pezic A, Chavez RA, Allen RC, Akikusa JD, et al. CLARITY - ChiLdhood arthritis risk factor identification sTudY. Pediatric rheumatology online journal. 2012;10(1):37.

10. Shenoi S, Shaffer ML, Wallace CA. Environmental risk factors and early-life exposures in juvenile idiopathic arthritis: a case-control study. Arthritis Care Res. 2016;68(8):1186-94.
11. Hyrich KL, Baildam E, Pickford H, Chieng A, Davidson JE, Foster $\mathrm{H}$, et al. Influence of past breast feeding on pattern and severity of presentation of juvenile idiopathic arthritis. Arch Dis Child. 2016;101(4):348-51.

12. Sverige. Socialstyrelsen: Kvalitet och innehåll i patientregistret : utskrivningar från slutenvård 1964-2006 och besök i öppenvård (exklusive primärvårdsbesök) 1997-2006. Stockholm: Socialstyrelsen; 2008.

13. Lunde AS, Lundeborg S, Lettenstrom GS, Thygesen L, Huebner J. The personnumber systems of Sweden, Norway, Denmark, and Israel. Vital and health statistics Series 2, Data evaluation and methods research. 1980;1(84):1-59.

14. Organization WH. Indicators for assessing breastfeeding practices. Geneva: World Health Organization; 1991. In.: WHO/CDD/SER/91.14

15. Rockhill B, Newman B, Weinberg C. Use and misuse of population attributable fractions. Am J Public Health. 1998;88(1):15-9.

16. Lande B, Andersen LF, Baerug A, Trygg KU, Lund-Larsen K, Veierod MB, et al. Infant feeding practices and associated factors in the first six months of life: the Norwegian infant nutrition survey. Acta Paediatr. 2003;92(2):152-61.

17. Atladottir $\mathrm{H}$, Thorsdottir I. Energy intake and growth of infants in Iceland-a population with high frequency of breast-feeding and high birth weight. Eur J Clin Nutr. 2000;54(9):695-701.

18. Michaelsen KF, Larsen PS, Thomsen BL, Samuelson G. The Copenhagen cohort study on infant nutrition and growth: breast-milk intake, human milk macronutrient content, and influencing factors. Am J Clin Nutr. 1994;59(3):600-11.

19. Briefel RR, Reidy K, Karwe V, Devaney B. Feeding infants and toddlers study: improvements needed in meeting infant feeding recommendations. J Am Diet Assoc. 2004;104(1 Suppl 1):s31-7.

20. Freeman V, van't Hof M, Haschke F. Patterns of milk and food intake in infants from birth to age 36 months: the euro-growth study. J Pediatr Gastroenterol Nutr. 2000;31(Suppl 1):S76-85.

21. Giovannini M, Riva E, Banderali G, Scaglioni S, Veehof SH, Sala M, et al. Feeding practices of infants through the first year of life in Italy. Acta Paediatr. 2004;93(4):492-7.

22. The National Board of Health and Welfare CfE. Statistics - health and diseases. Stockholm: Breast-feeding, Children Born 1999. In; 2001.

23. Prakken B, Albani S, Martini A. Juvenile idiopathic arthritis. Lancet. 2011; 377(9783):2138-49.

24. Gowdie PJ, Tse SM. Juvenile idiopathic arthritis. Pediatr Clin N Am. 2012;59(2):301-27.

25. Huttly SR, Barros FC, Victora CG, Beria JU, Vaughan JP. Do mothers overestimate breast feeding duration? An example of recall bias from a study in southern Brazil. Am J Epidemiol. 1990;132(3):572-5.

26. Launer L, Forman MR, Hundt GL, Sarov B, Chang D, Berendes HW, et al. Maternal recall of infant feeding events is accurate. J Epidemiol Community Health. 1992;46(3):203-6.

27. Akerblom HK, Knip M. Putative environmental factors in type 1 diabetes Diabetes Metab Rev. 1998;14(1):31-67.

28. Sansotta N, Piacentini GL, Mazzei F, Minniti F, Boner AL, Peroni DG. Timing of introduction of solid food and risk of allergic disease development: understanding the evidence. Allergol Immunopathol (Madr). 2013;41(5):337-45.

29. Prescott SL, Smith P, Tang M, Palmer DJ, Sinn J, Huntley SJ, et al. The importance of early complementary feeding in the development of oral tolerance: concerns and controversies. Pediatr Allergy Immunol. 2008;19(5):375-80

30. Garofalo R. Cytokines in human milk. J Pediatr. 2010;156(2 Suppl):S36-40.

31. Lonnerdal B. Bioactive proteins in human milk: mechanisms of action. J Pediatr. 2010;156(2 Suppl):S26-30.

32. Walker A. Breast milk as the gold standard for protective nutrients. J Pediatr. 2010;156(2 Suppl):S3-7.

33. Sjogren $Y M$, Tomicic S, Lundberg A, Bottcher MF, Bjorksten B, SverremarkEkstrom $E$, et al. Influence of early gut microbiota on the maturation of childhood mucosal and systemic immune responses. Clin Exp Allergy. 2009; 39(12):1842-51.

34. Maynard CL, Elson CO, Hatton RD, Weaver CT. Reciprocal interactions of the intestinal microbiota and immune system. Nature. 2012;489(7415):231-41.

35. Young VB. The intestinal microbiota in health and disease. Curr Opin Gastroenterol. 2012;28(1):63-9.

36. El Aidy S, Hooiveld G, Tremaroli V, Backhed F, Kleerebezem M. The gut microbiota and mucosal homeostasis: colonized at birth or at adulthood, does it matter? Gut Microbes. 2013;4(2):118-24.

37. Le Chatelier E, Nielsen T, Qin J, Prifti E, Hildebrand F, Falony G, et al. Richness of human gut microbiome correlates with metabolic markers. Nature. 2013;500(7464):541-6. 
38. Soyucen E, Gulcan A, Aktuglu-Zeybek AC, Onal H, Kiykim E, Aydin A. Differences in the gut microbiota of healthy children and those with type 1 diabetes. Pediatrics international : official journal of the Japan Pediatric Society. 2014:56(3):336-43.

39. Gronlund MM, Gueimonde M, Laitinen K, Kociubinski G, Gronroos T, Salminen S, et al. Maternal breast-milk and intestinal bifidobacteria guide the compositional development of the Bifidobacterium microbiota in infants at risk of allergic disease. Clin Exp Allergy. 2007;37(12):1764-72.

40. Martin R, Jimenez E, Heilig H, Fernandez L, Marin ML, Zoetendal EG, et al. Isolation of bifidobacteria from breast milk and assessment of the bifidobacterial population by PCR-denaturing gradient gel electrophoresis and quantitative real-time PCR. Appl Environ Microbiol. 2009;75(4):965-9.

41. Roger LC, Costabile A, Holland DT, Hoyles L, McCartney AL. Examination of faecal Bifidobacterium populations in breast- and formula-fed infants during the first 18 months of life. Microbiology. 2010;156(Pt 11):3329-41.

42. Aaltonen J, Ojala T, Laitinen K, Poussa T, Ozanne S, Isolauri E. Impact of maternal diet during pregnancy and breastfeeding on infant metabolic programming: a prospective randomized controlled study. Eur J Clin Nutr. 2011;65(1):10-9.

43. Azad MB, Becker AB, Guttman DS, Sears MR, Scott JA, Kozyrskyj AL. Canadian healthy infant longitudinal development study I: gut microbiota diversity and atopic disease: does breast-feeding play a role? J Allergy Clin Immunol. 2013;131(1):247-8.

44. Eckburg PB, Bik EM, Bernstein CN, Purdom E, Dethlefsen L, Sargent M, et al. Diversity of the human intestinal microbial flora. Science. 2005;308(5728):1635-8.

45. Lotz M, Gutle D, Walther S, Menard S, Bogdan C, Hornef MW. Postnatal acquisition of endotoxin tolerance in intestinal epithelial cells. J Exp Med. 2006;203(4):973-84.

46. Gill SR, Pop M, Deboy RT, Eckburg PB, Turnbaugh PJ, Samuel BS, et al. Metagenomic analysis of the human distal gut microbiome. Science. 2006; 312(5778):1355-9.

47. Palmer C, Bik EM, DiGiulio DB, Relman DA, Brown PO. Development of the human infant intestinal microbiota. PLoS Biol. 2007:5(7):e177.

\section{Submit your next manuscript to BioMed Central and we will help you at every step:}

- We accept pre-submission inquiries

- Our selector tool helps you to find the most relevant journal

- We provide round the clock customer support

- Convenient online submission

- Thorough peer review

- Inclusion in PubMed and all major indexing services

- Maximum visibility for your research

Submit your manuscript at www.biomedcentral.com/submit

) Biomed Central 